\title{
Pengaruh Marketing Mix Terhadap Keputusan Pembelian Pada Coffee Shop Janji Jiwa Jilid 200 di Padang
}

\author{
Edo Hamonangan Simatupang1, Hijriyantomi Suyuthie ${ }^{2}$ \\ ${ }^{1}$ Universitas Negeri Padang \\ ${ }^{2}$ Universitas Negeri Padang \\ e-mail: edohamonangan5@gmail.com
}

\begin{abstract}
ABSTRAK
Ambisi dari diadakannya penelitian berikut ialah untuk menganalisis besar kecilnya dampak marketing mix kepada keputusan pembelian konsumen di coffee shop Janji Jiwa Jilid 200 Padang. Metoda pada penelitian berikut adalah kuantitatif dengan upaya pendekatan asosiatif kausal yang melibatkan dua variabel. Dalam menentukan pengambilan sampel, digunakan teknik non probability sampling. Teknik pengambilan data yang dipakai pada penelitian berikut adalah dengan menyebar angket yang menggunakan skala likert dengan 32 buah jumlah pernyataan yang lebih dulu dites validitas dan reliabilitasnya. Data yang dideskripsikan dengan dites persyaratan analisis dan pengujian hipotesis yang menggunakan teknik analisis regresi linear sederhana serta koefisien determinan menggunakan software SPSS versi 20.00 .

Berlandaskan hasil penelitian: (1) Marketing Mix dikategorikan sangat baik (50,5\%), (2) Keputusan Pembelian tergolong sangat baik $(57,9 \%)$. Berdasarkan dari pengujian hipotesis regresi linear sederhana F 16.829 sig $0,000<0,05$, oleh sebab itu variabel marketing mix mampu mempengaruhi keputusan pembelian konsumen melalui nilai R Square 0,153. Marketing mix mendorong keputusan pembelian konsumen secara signifikan sebesar $15,3 \%$ dan $84,7 \%$ terpengaruh melalui faktor yang lainnya. Kemudian diperoleh nilai t 7,446 dengan sig $0,000<0,05$, sehingga diperoleh pengaruh yang siginikan antara kedua variabel. Selanjutnya nilai koefisien regresi senilai 0,463 serta nilai sig 0,000 $<0,05$, maksudnya per penambahan senilai 1 satuan marketing mix bisa menambah 0,463 satuan keputusan pembelian. Berlandaskan hasil penelitian disarankan agar pihak manajemen selalu memberikan upaya yang maksimal dalam meningkatkan penerapan marketing mix agar semakin mendorong keputusan pembelian konsumen.
\end{abstract}

Kata Kunci : Marketing Mix, Keputusan Pembelian. 


\section{PENDAHULUAN}

Di era saat ini jenis industri pariwisata yang sangat berkembang pesat adalah industri berupa akomodasi penginapan. Selain akomodasi penginapan, industri yang fokus bergerak di bidang food and beverage juga berkembang sangat pesat. Terlihat dengan banyaknya restoran, kafe maupun coffe shop yang tersebar diseluruh Indonesia. Coffee shop adalah suatu lokasi yang menggunakan meja dan kursi yang tersusun rapi juga sofa yang membuat nyaman, menyajikan aneka varian kopi serta kuliner ringan menjadi pendorong lalu disertai lantunan musik \& suasana nyaman yang bisa dinikmati oleh konsumen[1]. Salah satu brand Coffee Shop yang berada di kota Padang adalah Coffee Shop Janji Jiwa Jilid 200. Otlet Janji Jiwa Jilid 200 merupakan otlet ke 200 yang ada di Indonesia dan merupakan otlet pertama di kota Padang, yang ber-alamat kan di Jl. Batang Arau No.60, Berok Nipah, Kec. Padang Barat, Kota Padang, Sumatera Barat.

Pemahaman tentang keputusan pembelian konsumen yakni bagaimana suatu organisasi, golongan, dan individu perihal menentukan, membeli, memilih dan memakai barang atau jasa. Keputusan pembelian merupakan tahapan pada proses pengambilan keputusan dimana konsumen secara nyata melakukan pembelian[2]. Selanjutnya prosedur keputusan pembelian bermakna dimana konsumen akan menjalani 5 fase, yaitu sosialisasi masalah, mencari informasi, penilaian alternatif, keputusan pembelian, serta bagaimana konsumen memberikan reaksi pasca pembelian, yang telah dikaji jauh sebelum pembelian aktual dilakukan dan mempunyai pengaruh yang usang sesudah itu[3]. Keputusan pembelian ini dipengaruhi oleh marketing mix yang dilakukan oleh pihak terkait, agar tamu tertarik untuk mengunjungi.

Keputusan pembelian menjadi sangat penting bagi perusahaan karena melalui keputusan pembelian ini perusahaan dapat memperoleh laba. Keputusan pembelian juga akan menghasilkan dampak positif bagi perusahaan jika perusahaan dapat memberikan kepuasan bagi pembelinya, dimana pada fase ke5 dari keputusan pembelian terdapat perilaku pasca pembelian yang akan mendorong pembeli untuk merekomendasikan perusahaan jika pembeli tersebut merasa puas kepada perusahaan. Sebagaimana dikemukakan oleh[4] bahwa kepuasan pelanggan akan menjadi penentu keberhasilan suatu usaha/bisnis. Menurut[5] Marketing mix adalah seperangkat teknik pemasaran kerap dipakai perusahaan guna meraih target pemasarannya pada pasar sasaran. Marketing mix terdiri dari 4P : produk (product), harga (price), promosi (promotion), dan tempat (Place).

Maraknya trend brand coffee shop di kota Padang seperti Janji Jiwa, Lain Hati, Kulo, Foresthree, Kopi Soe, yang menjadi pilihan alternatif bagi konsumen, dan membuat persaing antar sesama coffee shop dalam menarik minat konsumen menjadi lebih tinggi. Peneliti juga menemukan konsumen yang mengalami pengalaman kurang memuaskan setelah membeli produk dikarenakan menurut konsumen tersebut rasa dari kopi yang kurang nendang dan biasa saja serta es yang terlalu banyak.

Keluhan lain yang peneliti temukan terkait dengan lokasi yang berada ditepi jalan utama yang membuat kesan bising menurut konsumen yang sudah melakukan kunjungan di Coffee Shop Janji Jiwa Jilid 200 Padang. Masalah lain yang peneliti temui adalah adanya perspektif dari beberapa konsumen yang menyatakan bahwa harga yang ditawarkan oleh Coffee Shop Janji Jiwa Jilid relatif mahal dan tidak sesuai dengan apa yang didapatkan oleh konsumen.

Berdasarkan pemaparan permasalahan-permasalahan yang terkait dengan keputusan pembelian, produk (product), harga (price) promosi (promotion), dan tempat (place) maka penelitian berikut penting diadakan guna mengetahui seberapa besar pengaruh marketing mix yang diupayakan pihak Coffee Shop Janji Jiwa Jilid 200 Padang agar konsumen melakukan pembelian pada produk yang Coffee Shop Janji Jiwa Jilid 200 Padang tawarkan.

\section{METODOLOGI PENELITIAN}

Penelitian berikut ber-jenis penelitian kuantitatif dengan menggunakan metode pendekatan asosiatif kausal. Hubungan kausal merupakan interaksi bersifat karena akibat, dan terdapat variabel yang 
mempengaruhi serta variabel yang dipengaruhi[6]. Dengan menyebarkan angket yang terdapat 32 buah jumlah pernyataan positif dan kemudian disebarkan kepada konsumen yang melakukan aktivitas kunjungan di Coffee Shop Janji Jiwa Jilid 200 Padang. Dalam menentukan pengambilan sampel ini digunakan upaya non probability sampling. Non probability sampling merupakan teknik yang tidak menyediakan peluang yang serupa bagi masing-masing populasi untuk dijadikan sampel[7]. Total sampel penelitian ini sejumlah 95 orang konsumen yang berkunjung di Coffee Shop Janji Jiwa Jilid 200 Padang. Penelitian ini memfokuskan pada teknik pengukuran skala likert dimana masing-masing tanggapan dari responden diberi skor 1 hingga 5, skala likert dipakai guna meninjau sikap, dan pendapat serta persepsi individu atau golongan pada kenyataan sosial[7]. Perihal menentukan pengaruh antar kedua variabel digunakan software SPSS versi 20 yang bertujuan untuk menemukan dan memaparkan data dengan cara melakukan tes normalitas, tes homogenitas, tes linearitas serta melakukan pengujian hipotesis menggunakan regresi linear sederhana.

\section{HASIL DAN PEMBAHASAN}

Berlandaskan pengkajian yang telah dilaksanakan peneliti kepada 95 responden yang terkait dengan pengujian variabel marketing mix, peneliti menemukan hasil penelitian tentang variabel marketing mix. Berikut hasil dari olahan data berdasarkan penelitian terkait dengan variabel marketing mix:

Tabel 1. Data Variabel Marketing Mix

\begin{tabular}{|c|c|c|c|}
\hline Kategori & Kelas Interval & Frekuensi & \% \\
\hline Sangat Baik & $\geq \mathbf{5 5 , 9 5}$ & $\mathbf{4 8}$ & $\mathbf{5 0 , 5}$ \\
\hline Baik & $\geq 46,65-<55,95$ & 42 & 44,2 \\
\hline Cukup Baik & $\geq 37,35-<46,65$ & 5 & 5,3 \\
\hline Buruk & $\geq 28,07-<37,35$ & 0 & 0 \\
\hline Sangat Buruk & $<28,07$ & 0 & 0 \\
\hline Jumlah & & $\mathbf{9 5}$ & $\mathbf{1 0 0}$ \\
\hline
\end{tabular}

Dari tabel 1 diatas dirangkum bahwa 50,5\% responden mengutarakan sangat baik, 44,2\% responden mengatakan baik, dan 5,3\% responden menyatakan cukup baik dan tidak adanya responden yang berpendapat buruk dan sangat buruk (0\%). Maka dapat dinyatakan bahwa marketing mix di Coffee Shop Janji Jiwa Jilid 200 Padang dikategorikan sangat baik.

Selanjutnya dari pengkajian yang sudah ditempuh oleh peneliti pada 95 responden yang terkait dengan pengujian variabel keputusan pembelian, peneliti memperoleh hasil penelitian tentang variabel keputusan pembelian. Berikut hasil olahan data yang telah dilakukan dari pengkajian terkait keputusan pembelian sebagai berikut:

Tabel 2. Data Variabel Keputusan Pembelian

\begin{tabular}{|c|c|c|c|}
\hline Kategori & Kelas Interval & Frekuensi & \% \\
\hline Sangat Baik & $\geq \mathbf{7 2}$ & $\mathbf{5 5}$ & $\mathbf{5 7 , 9}$ \\
\hline Baik & $\geq 60-<72$ & 35 & 36,8 \\
\hline Cukup Baik & $\geq 48-<60$ & 5 & 5,3 \\
\hline Buruk & $\geq 36-<48$ & 0 & 0 \\
\hline Sangat Buruk & $<36$ & 0 & 0 \\
\hline Jumlah & & $\mathbf{9 5}$ & $\mathbf{1 0 0}$ \\
\hline
\end{tabular}

Berdasarkan tabel diatas dapat dilihat bahwa 57,9\% responden menyatakan sangat baik, 36,8\% responden mengatakan baik, dan 5,3\% responden yang menyampaikan cukup baik, serta tidak adanya responden yang mengutarakan buruk dan sangat buruk (0\%). Maka dapat ditarik kesimpulan bahwa keputusan pembelian di Coffee Shop Janji Jiwa Jilid 200 Padang dikategorikan sangat baik 
Analisis regresi linear telah melalui uji persyaratan analisis berupa

1. Uji Normalitas diadakan memakai uji kolmogorov smirnov dengan nilai sig variabel marketing mix (X) 0,444 dan nilai sig untuk variabel keputusan pembelian (Y) 0,191 dengan taraf signifikan senilai > 0,05. Lalu dapat dimaknai bahwasannya kedua data varibel tersebut normal.

Tabel 3. Hasil Uji Normalitas

One-Sample Kolmogorov-Smirnov Test

\begin{tabular}{|ll|r|r|}
\hline & & $\begin{array}{r}\text { Marketing } \\
\text { Mix }\end{array}$ & $\begin{array}{r}\text { Keputusan } \\
\text { Pembelian }\end{array}$ \\
\hline $\mathrm{N}$ & Mean & 55 & 95 \\
Normal & Std. & 6.5579 & 72.7684 \\
Parameters $^{\mathrm{a}, \mathrm{b}}$ & Deviation & 6.99501 & 8.27255 \\
& Absolute & .089 & .111 \\
Most Extreme & Positive & .064 & .059 \\
Differences & Negative & -.089 & -.111 \\
Kolmogorov-Smirnov Z & .864 & 1.084 \\
Asymp. Sig. (2-tailed) & $\mathbf{. 4 4 4}$ & $\mathbf{. 1 9 1}$ \\
\hline
\end{tabular}

a. Test distribution is Normal

2. Uji Homogenitas dilakukan memakai uji Testhomogenity of variance sig senilai 0,111 ambang signifikan > 0,05. Maka dimaknai bahwasannya data bersumber dari varians serupa.

\section{Tabel 4. Hasil Uji Homogenitas}

Test of Homogeneity of Variances

Keputusan Pembelian (Y)

\begin{tabular}{|r|r|r|r|}
\hline $\begin{array}{c}\text { Levene } \\
\text { Statistic }\end{array}$ & df1 & df2 & Sig. \\
\hline 1.494 & 20 & 70 & $\mathbf{. 1 1 1}$ \\
\hline
\end{tabular}

3. Uji Linearitas diperoleh hasil dengan nilai sig 0,139 dengan ambang signifikan senilai > 0,05 kemudian disimpulkan kedua variabel penelitian ini terdapat hubungan linear secara relevan.

Tabel 5. Hasil Uji Linearitas ANOVA Table

\begin{tabular}{|c|c|c|c|c|c|c|c|}
\hline & & & $\begin{array}{l}\text { Sum of } \\
\text { Squares }\end{array}$ & Df & $\begin{array}{l}\text { Mean } \\
\text { Square }\end{array}$ & $\mathrm{F}$ & Sig. \\
\hline \multirow{6}{*}{$\begin{array}{l}\text { Keput } \\
\text { usan_- } \\
\text { pemb } \\
\text { elian } \\
* \\
\text { Marke } \\
\text { ting_- } \\
\text { mix }\end{array}$} & & $\begin{array}{l}\text { (Combin } \\
\text { ed) }\end{array}$ & 2707.878 & 24 & 112.828 & 2.120 & .008 \\
\hline & Between & Linearity & 985.732 & 1 & 985.732 & 18.524 & .000 \\
\hline & Groups & $\begin{array}{l}\text { Deviatio } \\
n \quad \text { from }\end{array}$ & 1722.146 & 23 & 74.876 & 1407 & 139 \\
\hline & & Linearity & & & & & \\
\hline & \multicolumn{2}{|c|}{ Within Groups } & 3725.027 & 70 & 53.215 & & \\
\hline & \multicolumn{2}{|l|}{ Total } & 6432.905 & 94 & & & \\
\hline
\end{tabular}




\section{Pengujian hipotesis}

Pengujian hipotesis penelitian ini menggunakan analisis regresi linear, yang perlukan untuk melihat seberapa besar pengaruh antar variabel yang diteliti.

Tabel 6. Nilai Signifikansi

ANOVA ${ }^{a}$

\begin{tabular}{|c|c|c|c|c|c|c|}
\hline & & $\begin{array}{l}\text { Sum of } \\
\text { Squares }\end{array}$ & Df & $\begin{array}{l}\text { Mean } \\
\text { Square }\end{array}$ & $\mathrm{F}$ & Sig. \\
\hline \multirow{3}{*}{1} & Regression & 985.732 & 1 & \multirow{3}{*}{$\begin{array}{r}985.732 \\
58.572\end{array}$} & \multirow[t]{3}{*}{16.829} & \multirow[t]{3}{*}{$.000^{\mathrm{b}}$} \\
\hline & Residual & 5447.173 & 93 & & & \\
\hline & Total & 6432.905 & 94 & & & \\
\hline
\end{tabular}

Dari hasil dari pengujian hipotesis, didapat nilai Frekuensi 16.829, sign 0,000 $<0,05$ dapat dijelaskan bahwa variabel marketing mix dapat mempengaruhi keputusan pembelian konsumen secara signifikan. Sehingga dikatakan Ha telah diterima serta Ho tidak diterima.

Tabel 7. Koefisien Regresi Variabel X Terhadap Variabel Y Coefficients $^{\mathrm{a}}$

\begin{tabular}{|c|c|c|c|c|c|c|}
\hline \multirow{2}{*}{\multicolumn{2}{|c|}{ Model }} & \multicolumn{2}{|c|}{$\begin{array}{c}\text { Unstandardized } \\
\text { Coefficients } \\
\end{array}$} & $\begin{array}{l}\text { Standardized } \\
\text { Coefficients }\end{array}$ & \multirow[t]{2}{*}{$\mathrm{T}$} & \multirow[t]{2}{*}{ Sig. } \\
\hline & & $\mathrm{B}$ & Std. Error & Beta & & \\
\hline & (Constant) & 47.048 & 6.319 & & 7.446 & .000 \\
\hline 1 & $\begin{array}{l}\text { Marketing } \\
\text { Mix }\end{array}$ & .463 & .113 & .391 & 4.102 & .000 \\
\hline
\end{tabular}

Berlandaskan dari tabel koefien regresi diatas terdapat koefisien regresi senilai 0.463 nilai Sig 0.000 $<0.05$. Dengan itu didapat persamaan regresi nya :

$$
Y=47,048+0,463 X
$$

Maknanya per penambahan senilai 1 satuan marketing mix akan menambah 0.463 satuan nilai keputusan pembelian konsumen.

Tabel 8. Hasil Test $\mathrm{R}$ Square Variabel X dan Y

Model Summary

\begin{tabular}{|c|r|r|r|r|}
\hline Model & $\mathrm{R}$ & $\begin{array}{c}\mathrm{R} \\
\text { Square }\end{array}$ & $\begin{array}{r}\text { Adjusted } \\
\mathrm{R} \text { Square }\end{array}$ & $\begin{array}{r}\text { Std. Error of } \\
\text { the Estimate }\end{array}$ \\
\hline 1 & $.391^{\mathrm{a}}$ & .153 & .144 & 7.65322 \\
\hline
\end{tabular}

Berlandaskan dari tabel diatas didapat hasil uji $\mathrm{R}$ Square $=0.153$. Jadi pengaruh marketing mix terhadap keputusan pembelian konsumen ialah 15,3\% sedangkan melalui faktor lain senilai 84,7\%.

\section{Pembahasan}

\section{Marketing Mix (X)}

Berlandaskan hasil pengkajian, dapat disimpulkan bahwa dari 95 responden, variabel marketing mix dapat digolongkankan sangat baik $50,5 \%$, lalu pada indikator produk $73,7 \%$ responden mengutarakan sangat baik, dalam indikator harga responden mengutarakan sangat baik 46,3\%, indikator promosi dikategorikan sangat baik 51,5\%, lalu pada indikator tempat $49,4 \%$ digolongkan baik. Artinya berdasarkan pengkajian yang telah dilakukan, diperoleh hasil marketing mix di Coffee Shop Janji Jiwa termasuk dalam kategori sangat baik. 
Marketing mix merupakan serangkaian indera pemasaran fleksibel yang bisa dikontrol misalnya produk, harga, kenaikan harga \& loka yang dipadukan perusahaan guna membentuk tanggapan yang diinginkan perusahaan pada pasar sasaran[9].

Penelitian berikut sejalan dengan penelitian yang lebih dahulu dilakukan oleh[10] Bauran pemasaran mempengaruhi kepuasan konsumen di restoran Lamun Ombak sebesar 37,1\%. Sementara senilai $62,9 \%$ dipengaruhi oleh variabel lain yang tidak terkait dalam ruang lingkup penelitian tersebut.

Berlandaskan uraian diatas menjelaskan bahwa marketing mix sangat berperan penting bagi perusahaan, karena jika marketing mix telah diterapkan dengan baik maka akan berdampak terhadap keputusan pembelian konsumen yang nantinya akan menambah pendapatan coffee shop melalui penjualan produk.

\section{Keputusan Pembelian (Y)}

Berlandaskan hasil pengkajian, dapat dijelaskan bahwa menurut 95 responden, variabel keputusan pembelian dapat digolongkan sangat baik 57,9\%. Kemudian dalam indikator pencarian kebutuhan $63,1 \%$ responden menyampaikan sangat baik, dalam indikator pencarian informasi yg dicapai 55,8\% responden menyampaikan sangat baik, dalam indikator penilaian alternatif 64,2\% responden menyampaikan sangat baik, dalam indikator keputusan pembelian $67,4 \%$ responden menyampaikan sangat baik, dalam indikator kelakuan pasca pembelian $79 \%$ responden menyampaikan sangat baik. Artinya berdasarkan pengkajian diperoleh keputusan pembelian konsumen di Coffee Shop Janji Jiwa Jilid 200 Padang tergolong sangat baik.

Keputusan pembelian menurut[11] secara generik dimaknai sebagai bagian berdasarkan bagaimana konsumen memberikan reaksi pasca pembelian yaitu pemikiran mengenai bagaimana individu, golongan, kelompok memilah, membeli, menggunakan serta bagaimana barang, jasa atau pengalaman guna memenuhi kebutuhan \& asa konsumen. Merujuk dari penjelasan diatas menunjukkan bahwa pihak manajemen harus selalu berkreasi dalam mempengaruhi keputusan pembelian konsumen.

\section{Pengaruh Marketing Mix Terhadap Keputusan Pembelian}

Dari hasil tes hipotesis yang telah diadakan guna memperdalam berapa derajat pengaruh antara variabel marketing mix terhadap keputusan pembelian yang dilakukan oleh konsumen di Coffee Shop Janji Jiwa Jilid 200 Padang yang dilakukan melalui bantuan software SPSS versi 20.00 tersebut diperoleh nilai signifikansi sebesar $0,000<0,05$, dengan koefisien regresi sebesar 0,463 satuan. Sementara dihasilkan koefisien determinan (R Square) 0,153, maknanya ditemukan pengaruh variabel marketing mix terhadap keputusan pembelian konsumen senilai 0,153 $(15.3 \%)$, sementara pengaruh melalui faktor lain senilai $84,7 \%$. Oleh karena itu pada pengkajian ini hipotesis yang diterima adalah Ha serta Ho ditolak. Marketing mix berpengaruh pada keputusan pembelian konsumen dikarenakan marketing mix adalah bagian dari faktor-faktor yang mampu mempengaruhi keputusan pembelian konsumen di Coffee Shop Janji Jiwa Jilid 200 Padang. Banyak faktor lain yang dapat mempengaruhi minat ataupun keputusan pembelian konsumen selain dari factor marketing mix, diantaranya seperti faktor harga, citra atau image, motivasi dan gaya hidup, kelompok acuan maupun faktor keramah-tamahan yang dirasakan konsumen saat menerima pelayanan[12].

Berlandaskan dari hasil penelitian diatas dapat dimaknai bahwa marketing mix mempengaruhi keputusan pembelian konsumen secara positif dan signifikan. Maka disimpulkan bahwa semakin mumpuni pihak manajemen dalam menerapkan marketing mix akan semakin besar tingkat keputusan pembelian konsumen di Coffee Shop Janji Jiwa Jilid 200 Padang. 


\section{KESIMPULAN}

Berdasarkan hasil penelitian tentang pengaruh marketing mix terhadap keputusan pembelian yang dilakukan konsumen di Coffee Shop Janji Jiwa, maka dapat ditarik kesimpulan :

1. Variabel marketing mix berdasarkan 4 indikator yang sudah ditetapkan menunjukkan secara keseluruhan dengan persentase nilai sebesar 50,5\% berada pada kelas interval $>55,95$ termasuk dalam kategori sangat baik.

2. Varibel keputusan pembelian berdasarkan 5 indikator yang sudah ditetapkan menunjukkan secara keseluruhan dengan persentase nilai sebesar 57,9\% berada pada kelas interval $>72$ digolongkan pada kategori sangat baik.

3. Ditemukan pengaruh signifikan antara marketing mix pada keputusan pembelian konsumen senilai $15,3 \%$ sementara pengaruh melalui faktor lain senilai $84,7 \%$. 


\section{DAFTAR PUSTAKA}

[1] A. Kurniawan, "Pengaruh Promosi terhadap Keputusan Pembelian Konsumen pada Nichol Coffee.," Manaj. Ekon. dan Bisnis Univ. Pandaran Semarang, vol. 1, 2016.

[2] P. Kotler and G. Amstrong, Manajemen Pemasaran (Prinsip-prinsip manajemen pemasaran), 12th ed. Jakarta, 2012.

[3] K. Amstrong Gary, Dasar-dasar Pemasaran, 9th ed. Jakarta: Erlangga, 2016.

[4] Welasasih, A., \& Suyuthie, H. (2020). Pengaruh Servicescape Terhadap Kepuasan Tamu di UNP Hotel and Convention Center. JURNAL KAJIAN PARIWISATA DAN BISNIS PERHOTELAN, 1(3), 119-123. https://doi.org/10.24036/jkpbp.v1i3.15372.

[5] K. L. Kotler, Philip \& Keller, Marketing Management, 15th ed. 2016.

[6] Sugiyono, Metode Penelitian Kuantitaif. Bandung: Alfabeta, 2018.

[7] Sugiyono, Metode Penelitian Kuantitatif dan Kualitatif. Bandung: Alfabeta, 2017.

[8] P. and G. A. Kotler, Principle of Marketing, Global. New Jersey: Pearson, 2017.

[9] Kotler, Philip and Gary Armstrong. Principle of Marketing (Global Edition). New Jersey: Pearson Education Limited, 2017.

[10] Manvi, Kurnia Illahi. "PENGARUH BAURAN PEMASARAN TERHADAP KEPUASAN PELANGGAN PADA RESTORAN LAMUN OMBAK KOTA PADANG." JURNAL PENDIDIKAN DAN KELUARGA 11.1 (2019): 94-103.

[11] P. and G. A. Kotler, Principle of Marketing, Global. New Jersey: Pearson, 2017.

[12] Y. Abrian, A. Adrian, and R. Surendra, "Analysis of Factors Affecting Guest Decision in Purchase of Room Service in Hotel 'Grand Inna Padang,"” J. Bus. Hosp. Tour., vol. 5, no. 2, pp. 193-200, 2019, doi: http://dx.doi.org/10.22334/jbhost.v5i2.165. 